\title{
Algorithms for the detection of hazelnut oil in olive oil
}

\author{
By A. Cert and W. Moreda \\ Instituto de la Grasa (C.S.I.C.). Avda. Padre García Tejero, 4 \\ E - 41012 Sevilla, España. e-mail: wences@ cica.es
}

\section{RESUMEN}

\section{Algoritmos para la detección de aceite de avellana en aceite de oliva.}

La adición fraudulenta de aceite de avellana en aceite de oliva puede ser detectada sólo en altas proporciones (20-25\%), usando el $\Delta 7$-estigmastenol y la diferencia entre los triglicéridos con número de carbono equivalente igual a 42 , determinados experimentalmente por HPLC y teóricamente a partir de la composición de ácidos grasos ( $\triangle E C N 42)$. Se propone un nuevo método que consiste en la comparación de los valores de varios algoritmos con una base de datos de valores experimentales obtenidos de aceites de oliva virgen genuinos. Estos algoritmos son: $\mathrm{LLL}_{\exp }$ en función de \%L; (LLL/OLLLn) exp - (LLL/OLLn) teor en función de $\triangle E C N 44$ y (ECN44/LLL) exp en función de \%L; siendo: LLLexp, OLLn $n_{\exp }$ y ECN44 $4_{\exp }$ los porcentajes de los triglicéridos obtenidos por HPLC; LLL teor, OLLn teor y ECN44 calculados teóricamente a partir de la composición de ácidos grasos; $\triangle E C N 44$ la diferencia entre el valor experimental y teórico del ECN44; y finalmente \%L el porcentaje de ácido linoleico. La base de datos se ha recopilado considerando los valores obtenidos de aceites de oliva de diferentes composiciones de ácidos grasos y mezclas entre ellos. El método permite la detección de pequeños porcentajes ( $5 \%$ ) de aceites de avellana en aceites de oliva.

PALABRAS-CLAVE: Aceite de avellana - Aceite de oliva - Ésteres de ácidos grasos - ECN42 - ECN44 - Triglicéridos.

\section{SUMMARY}

\section{Algorithms for the detection of hazelnut oil in olive oil}

The fraudulent addition of hazelnut oil to olive oil can be only detected in high proportions $(20-25 \%)$ using the $\Delta 7$-stigmastenol and the difference between triacylglycerols of equivalent carbon number 42 , determined experimentally by HPLC and calculated theoretically from the fatty acid composition ( $\triangle \mathrm{ECN} 42$ ). A new method lies on a sequential comparison of the values of several algorithms with a database built with data obtained from genuine virgin olive oils. The algorithms are: LLL $L_{\exp }$ vs \%L; (LLL/OLLn) $)_{\exp }$ (LLL/OLLn)theor, vs $\triangle E C N 44$ and (ECN44/LLL) exp vs \%L; being: $L L n_{\exp }$ OLLn $n_{\exp }$ and ECN44 exp the percentage of triacylglycerols determined by HPLC, LLLitheor, OLLn theor and ECN44 theor, the percentage of those calculated theoretically from the fatty acid composition; $\triangle \mathrm{ECN} 44$ the difference between the experimental and theoretical value of $E C N 44$; and finally $\% \mathrm{~L}$ the percentage of linoleic acid. The database has been built considering the values obtained from olive oils of different fatty acid composition and from admixtures between them. The method allows the detection of low percentages of hazelnut oil in olive oil ( $5 \%)$.

KEY-WORDS: ECN42 - ECN44 - Fatty acid methyl esters Hazelnut oil - Olive oil - Triacylglycerol.

\section{INTRODUCTION}

The fraudulent addition of hazelnut oil to olive oil had being produced in the last years as a consequence of the high market price reached by the olive oil compared to the price of the hazelnut oil in larger producer as Turkey. The analytical methods and maximum limits included in the European Union Commission regulations (EEC/2568/91) referred to the olive oil allow the detection of hazelnut oil only in high proportions, because the composition of hazelnut oil is similar to the olive one.

The hazelnut oil from different origins (Spain, Italy, Turkey and U.S.A.) has been widely researched in fatty acid composition and sterols (Parcerisa et al, 1995; Rugraff et al, 1982; Gargano et al, 1981; Colombini et al, 1979; García Olmedo et al, 1978 and Van Dijck et al, 1995). Although, the sterol composition is very, similar between hazelnut and olive oil, the higher content in $\Delta 7$-stigmastenol present in hazelnut oil from Turkey allows their detection only when there is a high proportion of admixture, being it effectiveness limited (20-25\%).

The triacylglycerol composition (Parcerisa et al, 1995; Gargano et al, 1981 and Casadei et al, 1987) shows differences respecting to the olive oil, in particular the increase of triacylglycerols containing linoleic acid and the decrease of those containing palmitic and linolenic acid. The higher trilinolein content allows detection of fraudulent admixtures in variable proportions $(0-30 \%)$ depending on the varietal origin of the olive oil, being the limit of trilinolein $0.5 \%$ established in the EEC/2568/91 regulation. This parameter has been substituted in the EEC regulations by the differences between the percentage of triacylglycerols of equivalent carbon number 42 (ECN42) determined experimentally by HPLC and that theoretically calculated from the fatty acid composition (EEC/2472/97). This parameter improve slightly the detection level $(20-25 \%)$, being not so dependent on the olive oil cultivar. Therefore, it is necessary to look for new parameters for the detection of this fraud.

In this paper, relations between different triacylglycerol, the ones showing larger differences in both oils, have been studied and compared to those obtained theoretically from the fatty acid 
composition, in order to obtain algorithms to aid in the detection of low percentages of hazelnut oil in olive oil.

\section{EXPERIMENTAL}

\subsection{Materials}

All reagents were of analytical grade, except acetone and acetonitrile, which were of HPLC grade from Merck (Darmstad, Germany).

Silica gel cartridges of $1 \mathrm{~g}(6 \mathrm{ml})$ for solid phase extraction from Supelco (Bellefonte, PA, USA).

For the assays, virgin olive oils from different varietal origins were chosen in order to have a wide range of fatty acid composition. Virgin hazelnut oil from Turkey was used for the admixtures with olive oils.

\subsection{Oil purification}

The oil samples were purified by passing the oil through silica SPE. A silica SPE column was placed in a vacuum elution apparatus and washed under vacuum with $6 \mathrm{ml}$ of hexane. The vacuum was released to prevent the dryness of the column and then a solution of the oil $(0.12 \mathrm{~g})$ in $0.5 \mathrm{ml}$ of hexane was charged into the column. The solution was pulled through and then eluted with $10 \mathrm{ml}$ of hexane diethylether $(87: 13 \mathrm{v} / \mathrm{v})$ under vacuum. The combined elutes were homogenised and divided into two aliquots. Both solutions were evaporated to dryness in a rotary evaporator under reduced pressure at room temperature. The residues were dissolved, in $2 \mathrm{ml}$ of acetone for triacylglycerol (TAG) analysis and in $2 \mathrm{ml}$ of heptane for FAME analysis, respectively.

\subsection{HPLC analysis of triacylglycerols}

The analytical procedure is that described in the EEC Regulations (EEC/2568/91) using an HPLC column packed with particles of $0.4 \mu \mathrm{m}$ instead of the $0.5 \mu \mathrm{m}$ particles (León-Camacho and Cert, 1994).

A $10 \mu \mathrm{l}$ aliquot of the purified oil solution in acetone $(5 \%)$ was injected onto the HPLC system. The analyses were done on a Lichrosphere $100 \mathrm{RP}$. $18(4 \sim \mathrm{m})$ column (25 cm x $4 \mathrm{~mm}$ I.D.) using an HP 1050 pumping unit (Hewlett Packard, Avondale, PA, U.S.A.) and refractive index detector (HP 1047). The mobile phase was acetone acetonitrile (1:1) at a flow rate to elute the trilinolein at $13 \mathrm{~min}(1.2 \mathrm{ml} / \mathrm{min}$, approximately).

Special attention must be paid to the ECN42 ( 3 peaks) and ECN44 (4 peaks) as shown in Figure 1. $L L L_{\exp }$ and OLLn $n_{\exp }$ are the percentages of total area corresponding to the first and second peaks of the ECN42 group and the ECN44 is the percentage corresponding to the sum of the three peaks of the ECN44 group. In some cases the second peak of the ECN44 group splits in two peaks and then four peaks should be taken in account. For the calculation of the triacylglycerol percentage the peaks comprehended between ECN42 and ECN50 should be considered.

\subsection{Determination of fatty acid composition}

Fatty acid methyl esters (FAMES) were prepared by cold transmethylation with methanolic potash (IUPAC, 1987). To the solution of the purified oil in heptane $(2 \mathrm{ml}), 0.3 \mathrm{ml}$ of $2 \mathrm{~N}$ methanolic potash was added. The mixture was shaken vigorously for $30 \mathrm{~s}$, and then, left to settle for $10 \mathrm{~min}$. A $5 \mu \mathrm{l}$ aliquot of the upper layer was injected onto the gas chromatograph.



Figure 1

HPLC profile of an olive oil showing the peaks, which must be taken in account for the algorithm calculation. In the ECN44 peaks $1,2+2^{\mathrm{a}}$ and 3 should be taken in account 
The gas chromatographic analysis of FAMES was carried out according to the method described for the determination of FAMES trans-isomers (EEC/1429/92). A fused silica capillary column (SP $-2380,60 \mathrm{~m} \times 0.25 \mathrm{~mm}$ I.D., SUPELCO, Bellefonte, PA, U.S.A.) coated with cyanopropylsilicone $(0.20$ $\mu \mathrm{m}$ film thickness) and hydrogen as gas carrier were used. Operating conditions were: initial oven temperature $160^{\circ} \mathrm{C}$ for $13 \mathrm{~min}$., then increased at $1.5^{\circ} \mathrm{C} / \mathrm{min}$ until $190^{\circ} \mathrm{C}$ and maintained for $5 \mathrm{~mm}$. Temperatures of injector and detector were $225^{\circ}$ and $250^{\circ} \mathrm{C}$ respectively (León-Camacho and Cert, 1994). The oven temperature was adjusted to obtain the C18:3 peak eluting just before the $\mathrm{C} 20: 1$ peak. For the calculation of the percentage of each fatty acid, the areas of the peaks corresponding to the double bond position isomers were summed.

\subsection{Theoretical calculation of TAGs from FAME analysis}

The calculation of the theoretical percentage of TAGs from FAME analysis was carried out taking in account only the major fatty acids palmitic $P(C 16: 0)$, palmitoleic Po (C16:1), stearic 5 (C18:0), oleic O (C18:1), linoleic $L(C 18: 2)$, and linolenic $\operatorname{Ln}(C 18: 3)$. The percentages of these six fatty acids were normalised up to $100 \%$. According to the formula described in the EEC regulation (EEC/2472/97), a computer program was developed assuming an 1,3-random, 2-random distribution of the fatty acid in the glycerine molecule with the restriction in the percentages of saturated fatty acids in the 2-position (EEC/2472/97). To determine the TAG contribution to each HPLC peak, all the possible combinations among the 6 fatty acid isomers were determined. For each TAG the real equivalent carbon number was calculated according to the formula (Carelli and Cert, 1993).

$$
E C N 42=C N-2.52 b_{o}-2.43 b_{P_{0}}-2.27 b_{L}-2.09 b_{L n}
$$

The first peak of the ECN42 group includes the triacylglycerols $L L L$, and PoLL, the second one OLLn, PoPoPo, LPoPo, PoOLn. The three peaks of the ECN44 group comprehend OLL, PoOL, OOLn, PoPoO, PLL, PPoL, PPoPo, POLn, SLLn and SPoLn. The LnPP is not included for the calculation of the theoretical value of ECN44.

\section{RESULTS AND DISCUSSION}

The hazelnut oils show a fatty acid composition very homogeneous, while the olive oils have greater variations in the content of palmitic acid, oleic acid and mainly in linoleic acid. It can be seen from Table I that hazelnut oils have lower contents of palmitic, palmitoleic and linolenic acids. These differences are not enough significant to be used as an index for detecting the presence of hazelnut oil in olive oil. Similarly, the TAG composition of hazelnut oil is also very homogeneous as showed in Table II. On the other hand, olive oils show larger differences according to the variations in the fatty acid composition. Therefore, the detection of hazelnut oil in olive oil using the absolute values of triacylglycerol can not be used. A further step was looking for algorithms calculated from the experimental and theoretical values of TAGs that were quite different in both hazeinut and olive oils. The experimental trilinolein $\left(L L L_{\text {exp }}\right)$, the difference between the experimental and theoretical ratios of the LLL, and OLLn $\left(\Delta R_{1}\right)$, and the ratio between the experimental value of the ECN44 and the TAG OLLn $\left(\mathrm{R}_{\text {2exp }}\right)$ were the algorithms that showed grater differences (Table II).

Table 1

Fatty acid composition of different hazelnut and olive oil varieties

\begin{tabular}{|c|c|c|c|c|c|c|c|}
\hline Oil & $P$ & & Po & $\mathbf{s}$ & 0 & $L$ & $\operatorname{Ln}$ \\
\hline Hazelnut Turkey I & 5.0 & & 0.2 & 2.2 & 82.1 & 10.4 & 0.1 \\
\hline Hazelnut Turkey II & 4.9 & & 0.2 & 2.2 & 79.8 & 12.7 & 0.1 \\
\hline Hazelnut Spain & 4.9 & & 0.2 & 2.6 & 81.7 & 10.5 & 0.1 \\
\hline Olive «Picual» I & 12.6 & & 1.1 & 2.4 & 79.5 & 3.5 & 0.8 \\
\hline Olive "Picual" II & 10.2 & & 0.7 & 3.3 & 81.6 & 3.6 & 0.5 \\
\hline Olive "Hojiblanca" I & 10.5 & $"$ & 0.6 & 2.8 & 79.4 & 6.0 & 0.7 \\
\hline Olive "Hojiblanca» III & 8.0 & & 0.5 & 3.0 & 80.3 & 7.5 & 0.7 \\
\hline Olive "Hojiblanca" IV & 9.4 & & 0.5 & 3.3 & 77.5 & 8.6 & 0.7 \\
\hline Olive "Hojiblanca» II & 8.4 & & 0.5 & 3.1 & 76.8 & 10.5 & 0.7 \\
\hline Olive «Picholine" & 8.7 & & 0.6 & 2.2 & 75.2 & 12.4 & 0.9 \\
\hline Olive «Blanqueta» & 15.1 & & 1.2 & 2.1 & 65.2 & 15.1 & 0.7 \\
\hline Olive «Chamlali» I & 17.1 & & 2.1 & 2.7 & 61.4 & 16.1 & 0.6 \\
\hline Olive "Chamlali" II & 12.8 & & 0.8 & 3.0 & 64.8 & 17.9 & 0.7 \\
\hline
\end{tabular}


Table II

Triacylglycerol composition of different hazelnut and olive oil varieties

\begin{tabular}{|c|c|c|c|c|c|c|c|c|c|c|c|c|c|c|}
\hline Oil & LLL & OLLn & PLLn & OLL & $\begin{array}{l}\text { PLLt } \\
\text { OOLn }\end{array}$ & POLn & $\begin{array}{l}\text { OOLt+ } \\
\text { POOOO }\end{array}$ & $\begin{array}{l}\text { PLO+ } \\
\text { SLL. }\end{array}$ & 000 & POO & $\begin{array}{l}\text { POP+ } \\
\text { PLS }\end{array}$ & GOO & soo & POS \\
\hline Hazelnut Turkey I & 1.34 & - & - & 4.68 & 0.61 & - & 16.23 & 2.49 & 58.56 & 10.37 & 0.37 & 0.41 & 4.64 & 0.33 \\
\hline Hazelnut Turkey II & 1.80 & 0.07 & - & 5.49 & 0.96 & - & 17.70 & 3.29 & 52.44 & 11.29 & 0.76 & 0.55 & 4.57 & 0.50 \\
\hline Hazelnut Spain & 1.16 & - & - & 4.54 & 0.46 & - & 17.09 & 2.42 & 59.30 & 9.94 & 0.23 & 0.39 & 4.42 & 0.44 \\
\hline Olive "Picual» I & 0.01 & 0.17 & - & 0.46 & 1.60 & 0.70 & 7.73 & 3.45 & 47.23 & 25.51 & 3.79 & 0.78 & 5.12 & 1.51 \\
\hline Olive "Picual" II & 0.01 & 0.13 & - & 0.44 & 1.31 & 0.49 & 7.37 & 2.97 & 50.61 & 22.96 & 2.81 & 0.87 & 7.07 & 1.44 \\
\hline Olive «Hojiblanca" I & 0.03 & 0.15 & - & 1.02 & 1.73 & 0.68 & 10.79 & 4.07 & 46.63 & 22.10 & 2.66 & 0.82 & 5.49 & 1.12 \\
\hline Olive "Hojiblanca" III & 0.05 & 0.21 & 0.02 & 1.46 & 1.68 & 0.44 & 13.25 & 4.10 & 49.48 & 18.11 & 1.85 & 0.83 & 5.49 & 0.98 \\
\hline Olive «Hojiblanca" IV & 0.11 & 0.26 & 0.02 & 2.20 & 1.71 & 0.49 & 14.61 & 4.96 & 44.04 & 19.81 & 2.24 & 0.62 & 5.70 & 1.11 \\
\hline Olive «Hojiblanca» II & 0.15 & 0.28 & 0.05 & 2.87 & 1.89 & 0.41 & 16.67 & 5.15 & 44.35 & 17.64 & 1.71 & 0.76 & 5.47 & 1.05 \\
\hline Olive "Picholine" & 0.29 & 0.48 & 0.08 & 3.76 & 2.38 & 0.51 & 19.83 & 6.21 & 42.48 & 16.41 & 1.63 & 0.60 & 4.34 & 0.64 \\
\hline Olive "Blanqueta" & 0.45 & 0.33 & 0.13 & 4.87 & 2.80 & 0.60 & 17.72 & 11.71 & 28.13 & 21.99 & 4.23 & 0.49 & 3.19 & 0.88 \\
\hline Olive "Chamlali» I & 0.54 & 0.28 & 0.18 & 6.24 & 3.65 & 0.30 & 17.93 & 15.28 & 22.71 & 20.48 & 5.76 & 0.46 & 4.20 & 1.34 \\
\hline Olive "Chamlali" II & 0.82 & 0.45 & 0.20 & 6.91 & 3.54 & 0.22 & 20.47 & 10.69 & 29.60 & 17.87 & 2.93 & 0.43 & 4.08 & 0.89 \\
\hline
\end{tabular}

Table III

Values of the different parameters in hazelnut and olive oils

\begin{tabular}{|c|c|c|c|c|c|c|c|}
\hline Oil & $\begin{array}{l}\text { LLL theor. } \\
(\%)\end{array}$ & $P(\%)$ & $L(\%)$ & $\begin{array}{c}\text { LLL exp } \\
(\%)\end{array}$ & $\triangle \mathrm{ECN} 44$ & $\Delta \mathbf{R}_{1}$ & $R_{2 \exp }$ \\
\hline Hazelnut Turkey 1 & 0.22 & 4.9 & 12.7 & 1.80 & 0.97 & 14.5 & 3.0 \\
\hline Olive "Picual» I & 0.01 & 12.6 & 3.5 & 0.01 & 0.14 & 0.01 & 276 \\
\hline Olive "Picual" II & 0.01 & 10.2 & 3.6 & 0.01 & 0.44 & 0.01 & 224 \\
\hline Olive "Hojiblanca" I & 0.02 & 10.5 & 6.0 & 0.03 & 0.57 & 0.06 & 114 \\
\hline Olive «Hojiblanca» III & 0.05 & 8.0 & 7.5 & 0.05 & 0.23 & 0.06 & 69.1 \\
\hline Olive "Hojiblanca" IV & 0.07 & 9.4 & 8.6 & 0.11 & 0.64 & 0.19 & 40.2 \\
\hline Olive «Hojiblanca» II & 0.13 & 8.4 & 10.5 & 0.15 & 0.57 & 0.17 & 34.4 \\
\hline Olive "Picholine" & 0.22 & 8.7 & 12.4 & 0.29 & 0.62 & 0.16 & 23.0 \\
\hline Olive "Blanqueta" & 0.41 & 15.1 & 15.1 & 0.45 & 0.50 & 0.44 & 18.4 \\
\hline Olive "Chamlali» I & 0.55 & 17.1 & 16.1 & 0.54 & 1.46 & 0.44 & 19.0 \\
\hline Olive "Chamlali» II & 0.63 & 12.8 & 17.9 & 0.82 & 1.27 & 0.43 & 13.0 \\
\hline
\end{tabular}

In olive oil, the $L L L_{\text {exp }}$ has a direct relationship with the linoleic acid percentage while in hazelnut oil it has a higher value. Likely, the $\Delta R_{1}$ and $\triangle E C N 44$ parameters rise slightly with the linoleic acid percentage and a relationship between them can be established for the different levels of the theoretical trilinolein ( $L L L_{\text {theo }}$ ). In hazelnut oil the $\Delta R_{1}$ is high while $\triangle \mathrm{ECN} 44$ have values in the range of those of olive oil. In olive oil the $R_{\text {2exp }}$ parameter shows a significant decrease with the increase of the linoleic acid percentage, and it is always higher than in hazelnut oils.
The effect of the addition of hazelnut oil to olive oils can be seen in Table IV. In olive oils with low percentage of linoleic acid, a great increase of LLL $\mathrm{exp}_{\mathrm{p}}$ occurs while a slight increase of linolenic acid is observed. In contrast, in olive oils with high percentages of linoleic acid, a slight increase of the LLLexp when compared to the linolenic acid which remains constant or decreases. Therefore, the addition of hazelnut oil produce an increase of the $L L L_{\exp }$ value from the ones calculated in function of the linoleic acid percentage. Furthermore, it can be seen also from Table IV, that additions of hazelnut oil increase greatly the $\Delta R_{1}$ parameter while $\Delta E C N 44$ 
increase slightly. Finally, the $\mathbf{R}_{2 \exp }$ parameter diminishes significantly in olive oils with low and medium percentages of linoleic acid when hazelnut oil is added.

Table IV

Parameters changes for several olive oils adding different percentages of hazelnut oil

\begin{tabular}{|c|c|c|c|c|c|c|c|c|}
\hline Oil & $\begin{array}{l}\text { Hazelnut } \\
\text { (\%) }\end{array}$ & $\begin{array}{l}\text { LLL theor. } \\
\text { (\%) }\end{array}$ & L (\%) & $\begin{array}{c}P \\
(\%)\end{array}$ & $\underset{(\%)}{L L L \exp }$ & $\triangle E C N 44$ & $\Delta \mathbf{R}_{1}$ & $R_{2 \exp }$ \\
\hline \multirow{5}{*}{ Olive «Picual» I } & 0 & 0.01 & 3.50 & 12.50 & 0.01 & 0.14 & 0.01 & 276 \\
\hline & 2.5 & 0.01 & 3.76 & 12.31 & 0.05 & 0.44 & 0.29 & 43.9 \\
\hline & 5 & 0.01 & 3.99 & 12.12 & 0.10 & 0.52 & 0.57 & 26.3 \\
\hline & 7.5 & 0.01 & 4.22 & 11.93 & 0.15 & 0.61 & 0.77 & 20.3 \\
\hline & 10 & 0.01 & 4.45 & 11.74 & 0.19 & 0.68 & 1.02 & 15.3 \\
\hline \multirow{5}{*}{ Olive «Hojiblanca» II } & 0 & 0.13 & 10.30 & 8.30 & 0.15 & 0.57 & 0.17 & 34.4 \\
\hline & 2.5 & 0.13 & 10.47 & 8.22 & 0.19 & 0.61 & 0.32 & 27.4 \\
\hline & 5 & 0.13 & 10.53 & 8.13 & 0.23 & 0.65 & 0.46 & 22.8 \\
\hline & 7.5 & 0.13 & 10.66 & 8.05 & 0.26 & 0.68 & 0.59 & 19.5 \\
\hline & 10 & 0.13 & 10.78 & 7.97 & 0.30 & 0.71 & 0.75 & 15.5 \\
\hline \multirow{5}{*}{ Olive "Picholine" } & 0 & 0.22 & 12.32 & 8.66 & 0.29 & 0.62 & 0.16 & 23.0 \\
\hline & 2.5 & 0.22 & 12.33 & 8.57 & 0.33 & 0.65 & 0.26 & 20.2 \\
\hline & 5 & 0.22 & 12.35 & 8.35 & 0.37 & 0.68 & 0.35 & 18.0 \\
\hline & 7.5 & 0.22 & 12.35 & 8.35 & 0.40 & 0.72 & 0.43 & 16.6 \\
\hline & 10 & 0.22 & 12.36 & 8.28 & 0.44 & 0.75 & 0.53 & 15.1 \\
\hline \multirow{5}{*}{ Olive "Chamlali» II } & 0 & 0.63 & 17.80 & 12.70 & 0.74 & 1.27 & 0.15 & 13.6 \\
\hline & 2.5 & 0.60 & 17.59 & 12.43 & 0.77 & 1.31 & 0.18 & 13.1 \\
\hline & 5 & 0.59 & 17.47 & 12.24 & 0.79 & 1.34 & 0.27 & 12.6 \\
\hline & 7.5 & 0.58 & 17.34 & 12.04 & 0.82 & 1.36 & 0.42 & 12.1 \\
\hline & 10 & 0.56 & 17.21 & 11.85 & 0.85 & 1.38 & 0.56 & 11.5 \\
\hline
\end{tabular}

The results indicate that these three algorithms (LLL $L_{\exp }$ vs \% $; \Delta \mathrm{R}_{1}$ vs $\Delta \mathrm{ECN} 44 ; \mathrm{R}_{\text {2exp }}$ vs \%L) allows the detection of hazelnut oil in olive oils. Nevertheless, the admixtures of genuine olive oils of different linoleic acid contents yield similar effects that the addition of hazelnut oils, although in lesser magnitude. The values of the different parameters for admixtures of genuine olive oils of extreme percentages of linoleic acid are shown in Table V.

The settlement of limits for the $L L_{\mathrm{exp}}, \Delta \mathrm{R}_{1}$ and $R_{2 e \times p}$ parameters were determined experimentally in genuine oils having a wide range of linoleic and palmitic acid content. The compositions of admixtures of different olive oils in several proportions were also determined. From the results, theoretical parameters were calculated and the results corrected to include the repeatability error, being increased the LLLexp $_{\text {end }}$ and $\Delta R_{1}$ parameters by 0.03 and 0.15 respectively, and the $R_{\text {eexp }}$ calculated by the formula:

$$
\mathrm{R}_{\text {2exp }}=\frac{E C N 44_{\exp }-0.10}{L L L_{\text {exp }}+0.03}
$$

The genuine olive oils and the admixtures between them were classified in seven groups according to their theoretical trilinolein $(\mathrm{LLL}$ theor $<0.5$; $0.05-0.099 ; 0.10-0.199 ; 0.20-0.299 ; 0.30-$ $0.399 ; 0.40-0.499$ and $>0.50$ ). Moreover, for each group, the $L_{L L}$ exp vs \%L were depicted for the maximum values of $L L L_{\text {exp }}$ (Figure 2). Likely, the values of $\Delta R_{1}$ vSs $\triangle E C N 44$ were plotted and curves for the maximum and minimum values were established (Figure 3). Under the lower curve lied the values of monovarietal oils and the ones lying between those curves correspond to mixtures between oils. For these mixtures, the $R_{\text {zexp }} v s \% L$ were calculated and a curve was traced for the minimum values of the parameter (Figure 4). For each group 
Table V

Evolution of the parameters in admixtures of olive oils of different fatty acid composition

\begin{tabular}{|c|c|c|c|c|c|c|c|c|}
\hline Oil & $\%$ Admixture & $\begin{array}{l}\text { LLL theor. } \\
\qquad \%)\end{array}$ & $L(\%)$ & $\begin{array}{c}P \\
(\%)\end{array}$ & $\begin{array}{c}\text { LLL exp } \\
(\%)\end{array}$ & $\triangle \mathrm{ECN} 44$ & $\Delta R_{1}$ & $\mathbf{R}_{2 \exp }$ \\
\hline Olive "Prcual" II & - & 0.01 & 3.63 & 10.22 & 0.01 & 0.44 & 0.01 & 224 \\
\hline \multirow{6}{*}{$\begin{array}{l}\text { Olive "Chamlali" II } \\
+ \\
\text { "Picual" } \|\end{array}$} & $5: 95$ & 0.01 & 4.35 & 10.33 & 0.05 & 0.65 & 0.26 & 52.6 \\
\hline & $10: 90$ & 0.02 & 5.07 & 10.46 & 0.08 & 0.83 & 0.36 & 37.8 \\
\hline & $30: 70$ & 0.06 & 7.93 & 10.97 & 0.23 & 1.31 & 0.81 & 19.9 \\
\hline & $50: 50$ & 0.15 & 10.76 & 11.47 & 0.38 & 1.45 & 0.91 & 16.1 \\
\hline & $70: 30$ & 0.29 & 13.63 & 12.00 & 0.52 & 1.34 & 0.82 & 14.8 \\
\hline & $90: 10$ & 0.50 & 16.47 & 12.51 & 0.67 & 0.96 & 0.67 & 13.8 \\
\hline Olive "Chamlali" II & - & 0.63 & 17.86 & 12.76 & 0.79 & 1.27 & 0.43 & 13.0 \\
\hline
\end{tabular}

of theoretical trilinolein, different curves were obtained.

From the above results, the method is applied in a sequential procedure starting with the calculation of the experimental triacylglycerol and the theoretical one from the fatty acid composition. The first step consists in the comparison of the value of the experimental LLL, if the value is lower than 0.05 the oil is genuine. Otherwise one proceeds to the second step, which consists in the comparison of experimental values in function of the \% of linoleic acid. If the value is lower or equal to the limit, the oil is genuine, and if the value is above the limit, one proceeds to the third step, calculating the $\Delta R_{1}$ in function of the $\triangle E C N 44$. The value is bounded in two limits; if it is over the upper limit the oil is not genuine, if is below the lower limit the

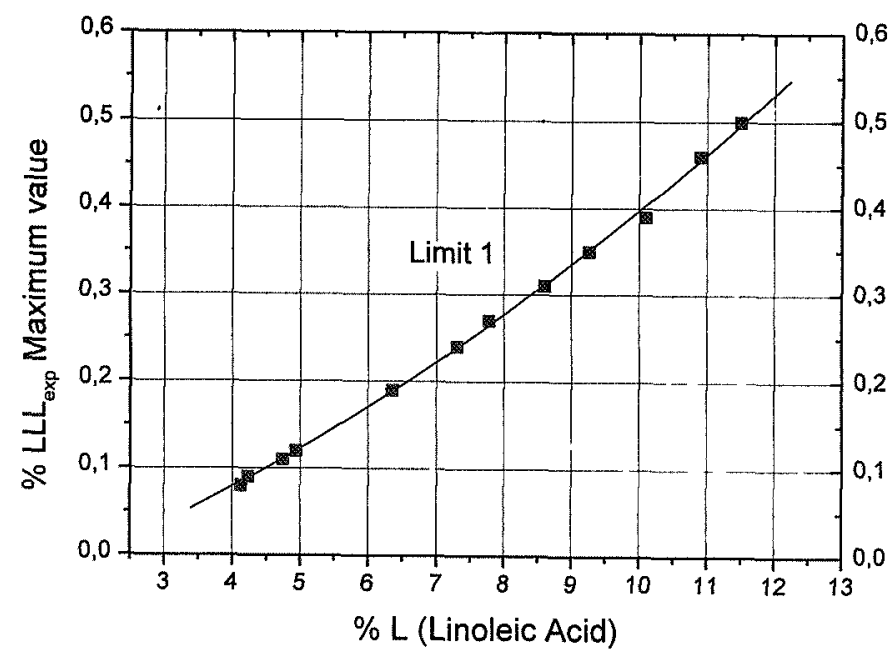

Figure 2

First limit for the classification of genuine and non-genuine olive oils (For LLLtheor. $<0.2$ ) oil is genuine and if the value is comprehended between both, one must proceeds to compare the next parameter. The last one consist in the calculation of $R_{2 \exp }$ parameter, again the parameter are bounded by a limit. In this case, if the value is above the limit the oil is genuine; but if is below the limit, the oil is not genuine. The flow diagram of the process is shown in the Figure 5.

To settle the detection level of the method, admixtures of each olive oil cultivar with several percentages $(2.5,5.0,7.5$ and $10 \%)$ of Turkish hazelnut oil were prepared. The method was applied concluding that all admixtures containing 7.5 and $10 \%$ of hazelnut oil and the majority of those containing $5.0 \%$ resulted in «no genuine oil». Besides, the majority of the admixtures containing

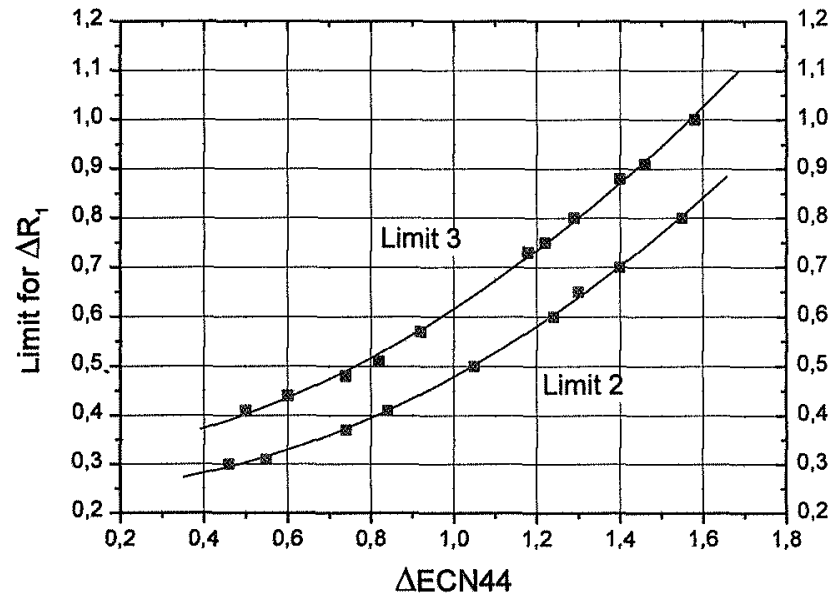

Figure 3

Second and third limits for the classification of genuine and non-genuine olive oils (For LLLtheor. $<0.05$ ) 


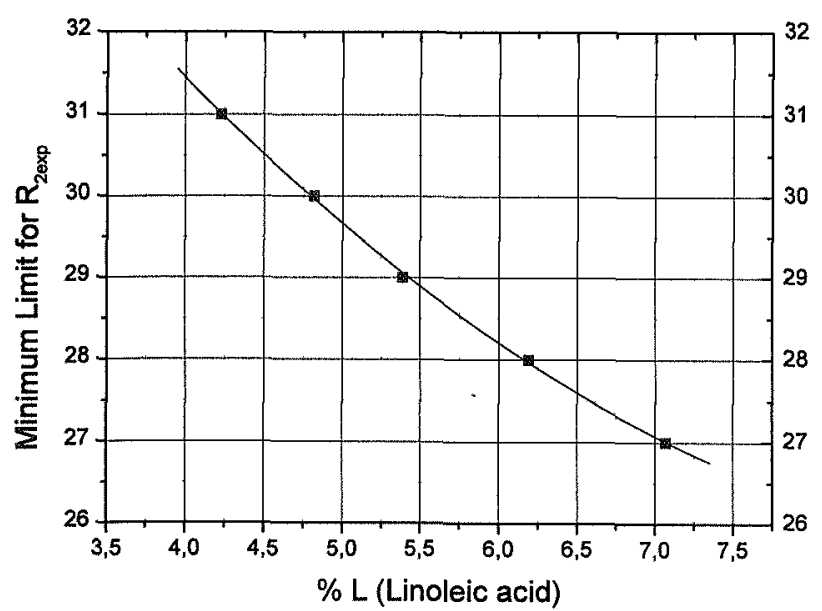

Figure 4

Fourth limit for the classification of genuine and non-genuine olive oils (For LLL theor. $<0.05$ )



Figure 5

Flow diagram of the sequential procedure for the detection of hazelnut oil in olive oil

$2.5 \%$ of hazelnut oil yielded «genuine oil» despite the parameter being very close to the limits. The results indicated that the method allows the detection of approximately $5.0 \%$ of hazelnut oil in olive oil.

Actually several laboratories are evaluating the method in order to establish the repeatability and reproducibility of the analytical procedure.

\section{ACKNOWLEDGEMENTS}

The authors wish to thank Manuel León-Camacho for the gas chromatographic and HPLC analysis of the oils. We also thank to Ministry of Agriculture for the financial support (INIA CA098-005).

\section{REFERENCES}

Carelli, A. A. and Cert, A. (1993). Comparative study of the determination of triacylglycerol in vegetable olís using chromatographic techniques. Journal of Chromatography A 630, 213-222.

Casadei, E. (1987). Primi resultati sulla ricerca di adulterazione de gli oh di oliva per aggiunta di olio di nocciole 0 oli esterificati mediante analisi dei trigliceridi. Rivista Italiana della Sostanze Grasse 64, 373-376.

Colombini, M., Vanoni, M. C., and Amelotti, G. (1979). Olio di noci, nocciole, mandorle, avocado; composizione sterolica. Rivista Italiana della Sostanze Grasse 56, 392-393.

Commission Regulation (EEC) No. $2568 / 91$ of $11^{\text {th }}$ of July 1991. On the characteristic of olive and olive pomace oils and on their analytical methods. Off. J. Eur. Commun., L248, 1 48, September 1991.

Commission Regulation (EEC) No. 1429/92 of $26^{\text {th }}$ of May 1992. On the modification of the Commission Regulation (EEC) No. 2568/91. Off. J. Eur. Commun., L50, 17-20, June 1992.

Commission Regulation (EC) No. $2472 / 97$ of $11^{\text {th }}$ of December 1997. On the modification of the Commission Regulation (EEC) No. 2568/91. Off. J. Eur. Commun., L341, 25-39, December 1997.

García Olmedo, R, Carballido, A. and Díaz Marquina, A. (1978). Contribución al estudio de los aceites de frutos secos españoles. Composición del insaponificable. I. Fracción de esteroles. Anales de Bromatología 30, 63-89.

Gargano, A., Magro, A., and Manzo, P. (1981). Caratteristiche chimiche del frutti di alcune delle principali cultivar di nocciolo. Industrie Alimentari 20, 104-106.

IUPAC. (1987). Standard methods for the analysis of oils, fats and derivatives; Blackwell: Oxford, $7^{\text {th }}$ Ed.; Method No. 2301 ; p. 123.

León-Camacho, M. and Cert, A. (1994). Recomendaciones para la aplicación de algunos métodos analíticos incluidos en el reglamento CEE 2568/91 relativo a las características de los aceites de oliva y de orujo de oliva. Grasas y Aceites 45, 395-401.

Parcerisa, J., Boatella, J., Codony, R., Rafecas, M., Castellote, A. I., García, J., López, A., and Romero, A. (1995). Comparison of fatty acid and triacylglycerol compositions of different hazelnut varieties (Corylus avellana L) cultivated in Catalonia (Spain). Journal of Agriculture and Food Chemistry 43, 13-16.

Rugraff L., Demanza, Ch., and Karleskind, A. (1982). Études des huiles oléiques à usage cosmétique et pharmaceutique. Parfums, Cosmétiques, Aromes 43, 59-67.

Van Dijck, M., Daenens, P., and Laruelle, L. (1995). Étude de l'nisaponifiable et de la composition des glycérides des huiles d'espèces de coryllus. Revue Francaise des Corps Gras 22, 617-622. 